\title{
Kelimpahan Mikroplastik Pada Sedimen Ekosistem Terumbu di Taman Nasional Laut Karimunjawa
}

\author{
Sakti Imam Muchlissin 1,3, Prastyo Abi Widyananto 1,3, Agus Sabdono2,3*, \\ Ocky Karna Radjasa ${ }^{4}$
}

\author{
'Magister IImu Kelautan, Fakultas Perikanan dan IImu Kelautan, Universitas Diponegoro \\ 2Departemen IImu Kelautan, Fakultas Perikanan dan IImu Kelautan, Universitas Diponegoro \\ 3Laboratorium Tropical Marine Biotechnology, Gedung J Laboratorium Kelautan dan Perikanan Lt.2 \\ Fakultas Perikanan dan Ilmu Kelautan, Universitas Diponegoro \\ JI. Prof. H. Soedarto, S.H, Tembalang, Semarang Jawa Tengah, 50275, Indonesia \\ 4 IImu Pengetahuan Kebumian Lembaga IImu Pengetahuan Indonesia \\ Jl. Jend, Gatot Subroto 10 Jakarta 12710 Indonesia \\ Email: agussabdonol@gmail.com
}

\begin{abstract}
The Abundance of Microplastics in Coral Reef Ecosystem Sediments in Karimunjawa Marine National Park
\end{abstract}

Eleven billion microplastic particles are entangled in coral reef ecosystems in the Asia-Pacific Region. The presence of microplastics in coral reef ecosystems in Indonesia, especially in the Karimunjawa Marine National Park, was found as many as 22.7 and 12.8 particles / kilogram samples in two locations. The presence of microplastics in coral reef ecosystems allows threats to the health of coral reefs. Therefore, the importance of this study is to complement the data on the distribution of microplastics in the Karimunjawa Marine National Park as an initial step for conservation and mitigation of the impact of plastic/ microplastic pollution. Sampling using purposive sampling method. Sediment collection using SCUBA set and sediment grab at a depth of 3 - 5 meters. \pm 1000 $g$ of sediment was taken and stored in double zip lock plastic. The samples were then analyzed by microplastics in the Tropical Marine Biotechnology Laboratory, FPIK UNDIP. The results showed that the greatest abundance of microplastics was in the Karang Tengah area with the number of microplastics 96 particles / kilogram, and the farthest in the Ujung Gelam and Lego was 11 particles / kilogram. Research shows that the abundance of microplastics in areas with human activities such as tourism, ports, and boat routes has a high abundance compared to conservation areas or areas with little human activity. It is hoped that the available data from this type of research will be able to produce decisions on conservation measures in Karimunjawa Marine National Park.

Keywords : Microplastic; Coral Reef Ecosystem; Karimunjawa

\begin{abstract}
Abstrak
Sebelas miliar partikel mikroplastik terjerat pada ekosistem terumbu karang di Kawasan Asia Pasifik. Keberadaan mikroplastik pada ekosistem terumbu karang di Indonesia, khususnya di Taman Nasional Laut Karimunjawa, ditemukan sebanyak 22,7 dan 12,8 partikel/kilogram sampel di dua lokasi. Keberadaan mikroplastik di ekosistem terumbu karang memungkinkan adanya ancaman terhadap kesehatan terumbu karang. Oleh karena itu pentingnya penelitian ini untuk melengkapi data sebaran mikroplastik di Kawasan Taman Nasional Laut Karimunjawa sebagai langkah awal konservasi dan mitigasi dari dampak polusi plastik/mikroplastik. Pengambilan sampel menggunakan metode purposive sampling. Pengambilan sedimen menggunakan SCUBA set dan sediment grab pada kedalaman $3-5$ meter. Sedimen diambil $\pm 1000 \mathrm{gr}$ dan disimpan dalam plastik double zip lock. Sampel kemudian dianalisis mikroplastik di laboratorium Tropical Marine Biotechnology, FPIK UNDIP. Hasil menunjukkan bahwa kelimpahan mikroplastik terbesar pada daerah karang tengah dengan jumlah mikroplastik 96 partikel/kilogram, dan terkecil pada perairan ujung gelam dan lego yaitu
\end{abstract}


sebanyak 11 partikel/kilogram. Penelitian menunjukkan bahwa kelimpahan mikroplastik didaerah dengan aktivitas manusia seperti pariwisata, pelabuhan, dan jalur kapal memiliki kelimpahan tinggi dibanding dengan daerah konservasi atau daerah dengan aktivitas manusia yang kecil. diharapkan dengan data yang tersedia dari penelitian sejenis ini, mampu menghasilkan keputusan terhadap langkah konservasi di Taman Nasional Laut Karimunjawa.

Kata kunci : Mikroplastik; Ekosistem Terumbu Karang; Karimunjawa

\section{PENDAHULUAN}

Sampah plastik adalah bentuk sampah laut paling umum yang menghadirkan masalah polusi global yang berkembang saat ini (Jambeck et al., 2015; Suaria et al., 2017; World Bank Group, 2018; Lamb et al., 2018). Kawasan Asia Timur merupakan penyumbang $50 \%$ keseluruhan sampah plastik dilautan (Jambeck et al., 2015) dan Indonesia tercatat setiap tahunnya menghasilkan 3,22 juta ton sampah yang tak tekelola dengan baik dan mengakibatkan prakiraan kebocoran 0,48 1,29 juta ton metrik sampah plastik ke lautan (World Bank Group, 2018). Diantara sampah plastik, 92,4\% nya berukuran kurang dari $5 \mathrm{~mm}$ dalam diameternya dan terdapat disemua perairan laut, partikel dengan ukuran kecil tersebut adalah mikroplastik (Suaria et al., 2017; Cózar et al., 2014; Santana et al., 2016). Lebih dari 11 miliar barang plastik diperkirakan terjerat di terumbu karang di Asia-Pasifik (Lamb et al., 2018).

Keberadaan mikroplastik juga terdeteksi pada ekosistem terumbu karang di Indonesia, sebanyak 48,3 \pm 13,98 partikel mikroplastik per kilogram sampel terdapat pada sedimen terumbu karang di Sekotong, Lombok (Cordova et al., 2018). Taman Nasional Laut Karimunjawa merupakan kepulauan yang terletak di sebelah utara daratan Jawa Tengah dengan total sekitar $80 \%$ dari pulaunya berpenghuni (Sabdono et al., 2019). Kepulauan ini memiliki habitat karang keras dengan dominasi karang branching Pocilloporidae dan Acroporidae (Tomascik et al., 1997). Taman Nasional yang juga merupakan destinasi wisata bahari sebagai daya tarik pariwisata bahari mancanegara no 1 di Jawa Tengah (DISPARBUD, 2018) masih menghasilkan sampah yang belum terkelola dengan baik. Sebagai kota/kabupaten yang berkomitmen mengurangi $70 \%$ sampah plastik ke laut, Karimunjawa masih menghasilkan
$6.901,08$ gr per tahun sampah pesisir yang 76,5 $\%$ merupakan sampah plastik (LKJ Ditjen PPKL, 2017). Potensi sampah plastik yang dihasilkan dari kegiatan manusia tersebut, memberikan ancaman tidak langsung terhadap ekosistem terumbu di sekitar Taman Nasional Laut Karimunjawa. Pada tahun 2018, Lie et al., (2018) mendeteksi keberadaan mikroplastik di Taman Nasional Laut Karimunjawa, sebanyak 22,7 dan 12,8 partikel per kilogram sampel yang ada di dua tempat yang berbeda.

Keberadaan mikroplastik di ekosistem terumbu karang memungkinkan adanya ancaman tidak langsung terhadap kesehatan terumbu karang (Hall et al., 2015; Connors, 2017; Reichert et al., 2018; Axworthy dan Padilla-Gamiño, 2019; Corona et al., 2020). Kurangnya data tentang sebaran mikroplastik yang terdapat di Kawasan Taman Nasional Laut Karimunjawa membuat Taman Nasional Laut ini terancam akan dampak tidak langsung dari sampah plastik/ mikroplastik. Oleh karena itu pentingnya dilakukan penelitian ini adalah untuk melengkapi data sebaran mikroplastik di Kawasan Taman Nasional Laut Karimunjawa sebagai langkah awal dalam kegiatan konservasi dan mitigasi dari dampak polusi plastik/ mikroplastik.

\section{MATERI DAN METODE}

Penelitian ini dilaksanakan pada Juli 2020, lokasi sampling berada di delapan belas titik sampling yang tersebar di delapan pulau dengan karakteristik yang berbeda - beda. Empat pulau dengan adanya intensitas antorpogenik yang aktif (Pulau Karimun, Pulau Menjangan, Pulau Cemara Kecil dan Besar), satu pulau dengan daerah konservasi (Pulau Bengkoang), dan Tiga pulau lainya dengan intensitas antropogenik yang kecil (Pulau Nyamuk, Pulau Katang, dan Pulau Menyawakan) 


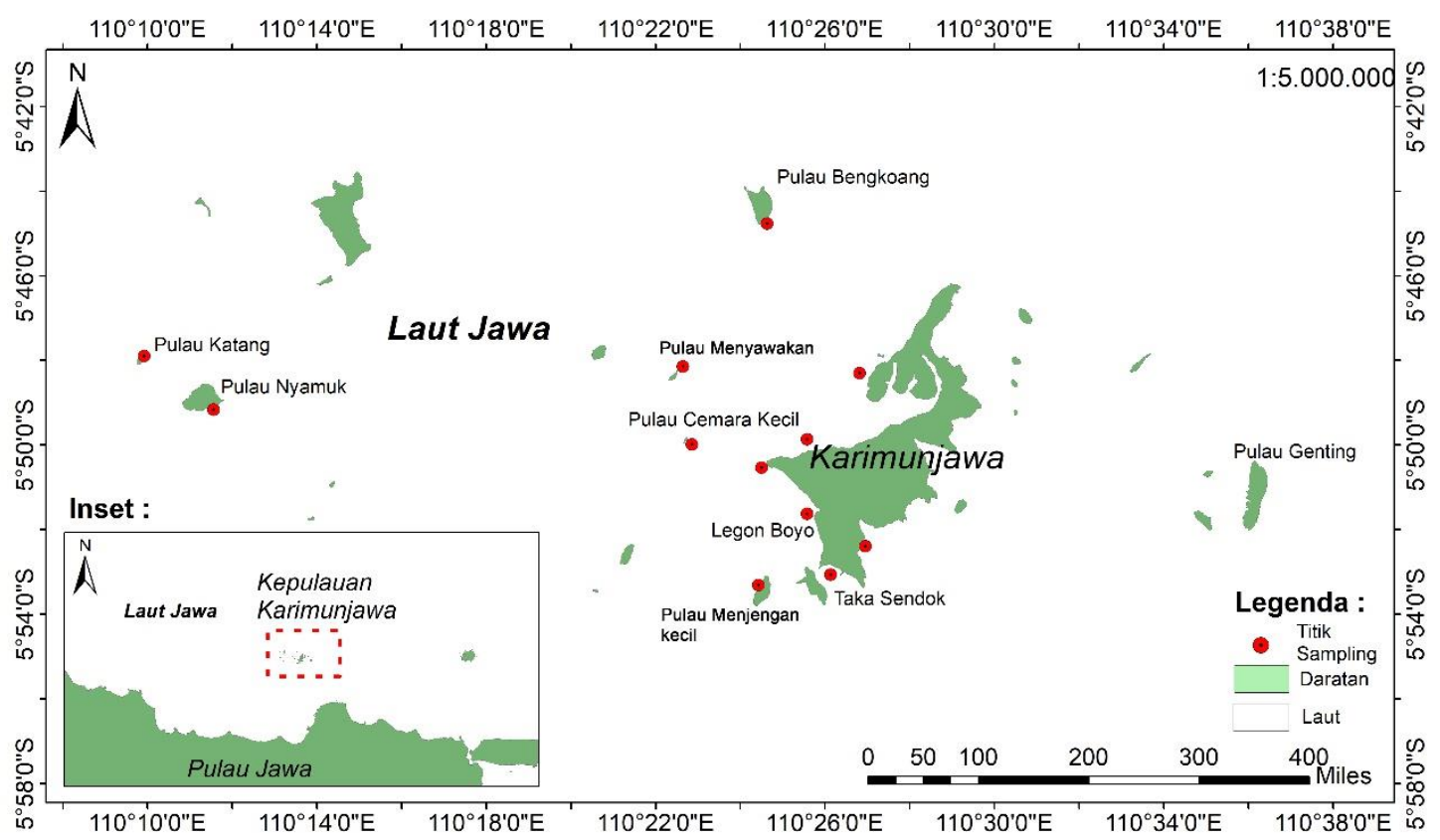

Gambar 1. Peta lokasi penelitian di Taman Nasional Laut Karimunjawa

Penelitian ini menggunakan bahan penelitian seperti air destilasi/ akuades, alumunium foil, saline water $(1,18 \mathrm{~g} / \mathrm{L} \mathrm{NaCl})$, kertas saring $0,45 \mu \mathrm{m}$. Adapun alat yang digunakan seperti SCUBA set dan sediment grab untuk pengambilan sampel, glas beker, petri disposal, mikroskop dan juga vacuum pump untuk kegiatan di laboratorium.

Pengambilan sampel menggunakan metode purposive sampling. Sampel sedimen menggunakan SCUBA set dan sediment grab pada kedalaman 3 - 5 meter. Sedimen dasar diambil $\pm 1000 \mathrm{gr}$ dan disimpan dalam wadah plastik double zip lock. Semua sampel kemudian dianalisis mikroplastik di laboratorium Tropical Marine Biotechnology, FPIK UNDIP.

Persiapan analisis mikroplastik pada sampel sedimen mengacu kepada metode ekstraksi mikroplastik oleh Cordova et al., 2018. Metode ini merupakan modifikasi gabungan dari metode ekstraksi mikroplastik sedimen oleh Thompson et al., 2014, Claessens et al,m 2011, dan Nor \& Obbard, 2014. Sampel sedimen dikeringkan pada suhu $74^{\circ} \mathrm{C}$ di oven selama 24 jam. Sampel sedimen yang sudah kering ditambahkan hydrogen peroksida $(\mathrm{H}-$ $\left.{ }_{2} \mathrm{O}_{2}\right) 30 \%$ dan di oven kembali pada suhu 80 $90{ }^{\circ} \mathrm{C}$, penambahan ini bertujuan untuk menghilangkan material organik yang terdapat pada sedimen. Sampel sedimen yang keluar buih, buih dihilangkan, kemudian ditambahkan saline water $(1,18 \mathrm{~g} / \mathrm{L} \mathrm{NaCl}+$ Akuades) dan didiamkan selama 24 jam. Setelah itu, melakukan proses penyaringan oleh vacuum pump dengan kertas saring Whatman Filter Selulosa (ukuran pori 0,45 $\mu \mathrm{m}$ ). Kertas Whatman Filter Selulosa hasil penyaringan disimpan ke dalam petri disposal steril dan dibungkus dengan parafilm/ wrap agar menghindari kontaminasi.

Pengamatan identifikasi dan kuantifikasi mikroplastik menggunakan mikroskop OLYMPUS CX23 dengan perbesaran 40X. Identifikasi mikropllastik dilakukan berdasarkan NOAA (2015), data diamati berdasarkan jumlah, bentuk, dan warna mikroplastik. Partikel yang diidentifikasi sebagai mikrolastik dengan kriteria ukuran antara $0.3-5 \mathrm{~mm}$. Partikel yang ragu ditentukan sebagai mikroplastik atau bukan, hot needle test (De Witte et al., 2014) dilakukan.

\section{HASIL DAN PEMBAHASAN}

Hasil yang didapat pada pengamatan mikroplastik menunjukkan bahwa kelimpahan mikroplastik terbesar terdapat pada daerah karang tengah dengan jumlah mikroplastik 96 
partikel / kilogram, dan terkecil terdapat pada daerah perairan ujung gelam dan lego yaitu sebanyak 11 partikel/ kilogram.

Hasil pengamatan, Karang Tengah $(96$ partikel/ kg), Pantai Bobby (40 partikel/ kg), Indonor (64 partikel/ kg), Pulau Tengah (53 partikel/ kg), Kapal Genteng (52 partikel/ kg), merupakan daerah dengan aktivitas manusia tinggi (pariwisata, dan jalur kapal). Sedangkan Taka Nyamplungan dan perkampungan wetan (22 partikel/ kg), Legon Boyo (19 partikel/ kg), Taka Sendok (34 partikel/ kg) dan area pulau Cemara (30 dan 29 partikel/ kg), adalah daerah dengan aktivitas manusia sedang (pariwisata). Lalu Pulau Katang (19 partikel/ kg), Pulau Nyamuk (13 partikel/ kg), Pulau Menjangan kecil (18 partikel/ kg), Perkampungan Lego (1 1 partikel/ $\mathrm{kg}$ ), dan Perairan Ujung Gelam (11 partikel/ $\mathrm{kg}$ ), adalah daerah dengan intensitas wisata dan aktivitas manusia yang kecil. Kemudian Pulau Bengkoang yang merupakan daerah konservasi terdapat 13 partikel/ kg. Variasi kelimpahan tersebut didasari oleh berbagai faktor, baik alami ataupun antropogenik. Menurut Yonkos et al (2014), skala yang berbeda dipengaruhi oleh tingkat urban atau manusia. Selain itu faktor alami yang mempengaruhi kelimpahan mikroplastik adalah pasang surut air laut (Sathish et al.,
2019). Konsentrasi mikroplastik ditemukan dua kali lebih besar pada garis pasang tinggi dari pada garis pasang rendah karena daerah pasang surut tetap terendam hampir sepanjang hari (Hengstmann et al., 2018; Kim et al., 2015).

Lokasi karang tengah memiliki jumlah mikroplastik paling besar, dikarenakan daerah ini merupakan daerah pemanfaatan pariwisata (DKKJI, 2015). Selain karang tengah, lokasi seperti Pulau Cemara, Pantai Bobby, Pulau Tengah, Kapal Genteng, dan Indonor, memiliki variasi kelimpahan mikroplastik yang cukup besar, dikarenakan daerah ini juga merupakan daerah pemanfaatan wisata dan dekat dengan pulau utama dengan populai penduduk tertinggi yaitu Pulau Karimun (BPS Kab Jepara, 2017). Kelimpahan mikroplastik dari sedang sampai tinggi di daerah tersebut diatas menjelaskan bahwa adanya aktifitas manusia (pariwisata) berdampak terhadap tingginya masukan mikroplastik. Cemaran plastik di lautan dimulai oleh daratan yang membawa bahan pencemar (salah satunya plastik) ke dalam sungai dan berakhir di lautan, selanjutnya pengaruh arus lautan menghantarkan sampah (plastik/ mikroplastik) ke daerah yang terpencil (Pawar et al., 2016). Oleh karena itu, partikel mikroplastik yang terdeteksi pada daerah dengan intensitas

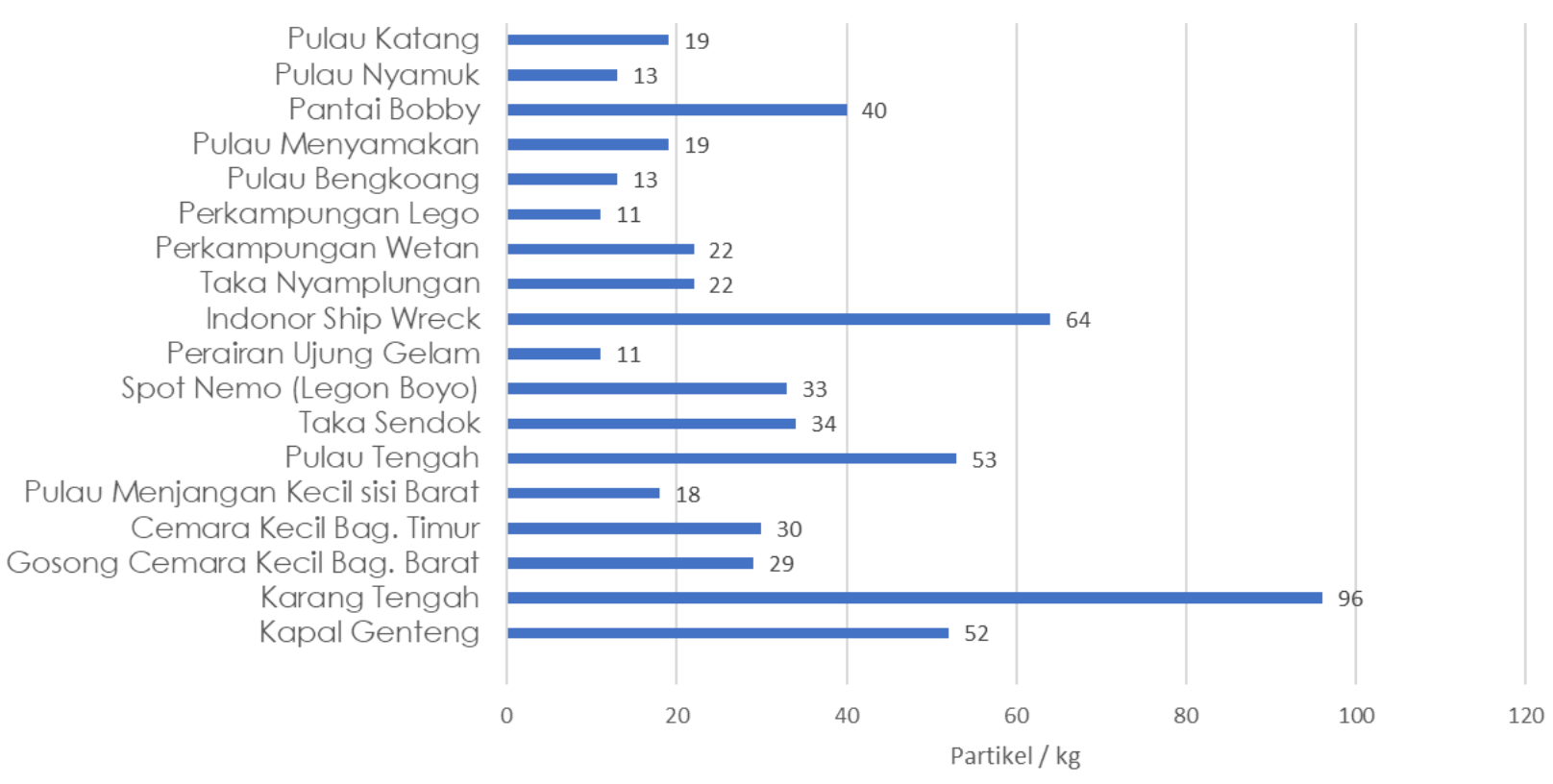

Gambar 2. Kelimpahan mikroplastik diberbagai titik sampling. 

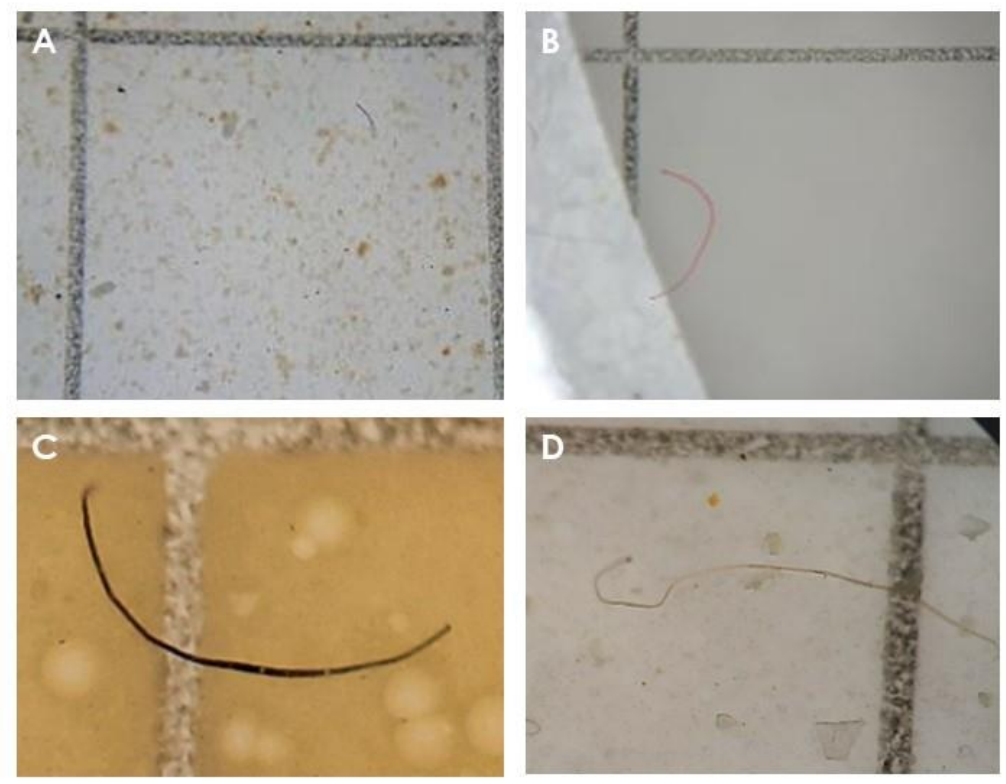

Gambar 3. Hasil pengamatan mikroplastik

manusia yang kecil seperti di Pulau Nyamuk dan Katang, bahkan daerah konservasi seperti Pulau Bengkoang, juga terdeteksi mikroplastik yang diduga disebabkan adanya pengaruh alami lautan yang mungkin membawa cemaran plastik/ mikroplastik dari daerah cemaran sampah yang lebih besar.

Daerah dengan kelimpahan mikroplastik yang besar juga merupakan daerah jalur lintas kapal, baik jalur kapal komersial (angkutan penumpang) ataupun kapal wisata. Pelabuhan dan aktivitas pelabuhan (jalur kapal) merupakan salah satu sumber cemaran plastik di lautan, Claessens et al., (2011) menjelaskan bahwa aktivitas di pelabuhan membuat area di sekitar pelabuhan memiliki densitas mikroplastik yang tinggi. Aktivitas tersebut terdiri atas sandar kapal dari kegiatan kapal wisata dan kapal industri. Cordova et al., (2019) menambahlan bahwa aktivitas populasi yang tinggi di hulu sungai dan aktivitas pelayaran yang tinggi menyebabkan masuknya mikroplastik ke perairan. Sebanyak $98 \%$ mikroplastik yang berada diperairan, itu semua bersumber dari kegiatan darat (Boucher \& Friot, 2017).

\section{KESIMPULAN}

Penelitian ini menunjukkan bahwa kelimpahan mikroplastik didaerah dengan aktivitas manusia seperti pariwisata, pelabuhan, dan jalur kapal memiliki kelimpahan yang tinggi dibanding dengan daerah konservasi ataupun daerah dengan aktivitas manusia yang kecil. Penelitian ini belum menjelaskan dengan rinci terkait dengan hubungan kelimpahan mikroplastik dengan kondisi Kesehatan terumbu karang disekitar daerah sampling. Kedepan, perlu adanya kajian yang lebih komprehensif terkait dengan hubungan kelimpahan mikroplastik dengan kesehatan terumbu karang. Dengan begitu, diharapkan dengan adanya data yang tersedia dari penelitian sejenis ini, mampu menghasilkan keputusan terhadap kebijakan dan langkah konservasi di Taman Nasional Laut Karimunjawa.

\section{UCAPAN TERIMA KASIH}

Penulis mengucapkan terima kasih kepada Direktorat Riset dan Pengabdian Masyarakat, Kementrian Riset dan Teknologi/ Badan Riset dan Inovasi Nasional Tahun Anggaran 2020 dengan No. SPK 22538/UN7.6.1/PP/2020.

\section{DAFTAR PUSTAKA}

Axworthy, J.B., \& Padilla-Gamiño, J.L. 2019. Microplastics ingestion and heterotrophy in thermally stressed corals. Scientific Reports, 9(1). doi : 10.1038/s41598-019- 
54698-7

Boucher, J., \& Friot, D. (2017). Primary microplastics in the oceans (IUCN). https://www.iucn.org/content/primarymicroplastics-oceans

Claessens, M., Meester, S. De, Landuyt, L. Van, Clerck, K. De, \& Janssen, C. R. (2011). Occurrence and distribution of microplastics in marine sediments along the Belgian coast. Marine Pollution Bulletin, 62(10):2199-2204. doi : 10.1016/ j.marpolbul.2011 1.06 .030

Connors, E.J. 2017. Distribution and biological implications of plastic pollution on the fringing reef of Mo' orea, French Polynesia. PeerJ, 2017(8). doi : 10.7717/peerj.3733

Cordova, Muhammad R., Hadi, T.A., \& Prayudha, B. 2018. Occurrence and abundance of microplastics in coral reef sediment: a case study in Sekotong, Lombok-Indonesia. Advances in Environmental Sciences, 10(1):23-29. doi : 10.5281/zenodo.1297719

Cordova, Muhammad Reza, Purwiyanto, A. I. S., \& Suteja, Y. (2019). Abundance and characteristics of microplastics in the northern coastal waters of Surabaya, Indonesia. Marine Pollution Bulletin, 142:183-188. doi : 10.1016/j.marpolbul. 2019.03.040

Corona, E., Martin, C., Marasco, R., \& Duarte, C. M. 2020. Passive and Active Removal of Marine Microplastics by a Mushroom Coral (Danafungia scruposa). Frontiers in Marine Science, 7:1-9. doi : 10.3389/ fmars.2020.00128

Cózar, A., Echevarría, F., González-Gordillo, J. I., Irigoien, X., Úbeda, B., Hernández-León, S., Palma, Á.T., Navarro, S., García-deLomas, J., Ruiz, A., Fernández-de-Puelles, M. L., \& Duarte, C.M. 2014. Plastic debris in the open ocean. Proceedings of the National Academy of Sciences of the United States of America, 111 (28):1023910244. doi : 10.1073/pnas.1314705111

Hall, N.M., Berry, K.L.E., Rintoul, L., \& Hoogenboom, M.O. 2015. Microplastic ingestion by scleractinian corals. Marine Biology, 162(3):725-732. doi : 10.1007/s0 0227-015-2619-7

Jambeck, J.R., Ji, Q., Zhang, Y.G., Liu, D., Grossnickle, D.M., \& Luo, Z.X. 2015. Plastic waste inputs from land into the ocean. Science, 347(6223):764-768. doi : 10.1126/ science. 1260879

Lamb, J.B., Willis, B.L., Fiorenza, E.A., Couch, C. S., Howard, R., Rader, D.N., True, J.D., Lisa, A.K., Ahmad, A., Jompa, J., \& Harvell, C.D. 2018. Commentary: Plastic waste associated with disease on coral reefs. Frontiers in Marine Science, 5:26-29. doi : 10.3389/fmars.2018.00237

Pawar, P.R., Shirgaonkar, S.S., \& Patil, R.B. 2016. Plastic marine debris: Sources, distribution and impacts on coastal and ocean biodiversity. Pencil : Publication of Biological Sciences, 3(1):40-54.

Reichert, J., Schellenberg, J., Schubert, P., \& Wilke, T. 2018. Responses of reef building corals to microplastic exposure. Environmental Pollution, 237:955-960. doi : 10.1016/j.envpol.2017.11.006

Sabdono, A., Radjasa, O. K., Trianto, A., Sarjito, Munasik, \& Wijayanti, D.P. 2019. Preliminary study of the effect of nutrient enrichment, released by marine floating cages, on the coral disease outbreak in Karimunjawa, Indonesia. Regional Studies in Marine Science, 30:100704. doi : 10.1016/j.rsma.2019.100704

Santana, M. F. M., Ascer, L. G., Custódio, M. R., Moreira, F.T., \& Turra, A. 2016. Microplastic contamination in natural mussel beds from a Brazilian urbanized coastal region: Rapid evaluation through bioassessment. Marine Pollution Bulletin, 106(1-2):183-189. doi : 10.1016/j.marpolbul.2016.0

Sathish, N., Jeyasanta, K.I., \& Patterson, J. 2019. Abundance, characteristics and surface degradation features of microplastics in beach sediments of five coastal areas in Tamil Nadu, India. Marine Pollution Bulletin, 142:112-118. doi : 10.1016/j.mar polbul.2019.03.037

Suaria, G., Avio, C. G., Lattin, G., Regoli, F., \& Aliani, S. 2017. Floating Microplastics in the South Adriatic Sea. In Fate and Impact of Microplastics in Marine Ecosystems. Elsevier Inc. doi : 10.1016 /b978-0-12812271-6.00049-1

World Bank Group. 2018. Hotspot Sampah Laut Indonesia. Public Disclosure Authorized, April, 1-49. http://documents.worldbank. org/curated/en/642751527664372193/pd f/126686-INDONESIA-29-5-2018-14-34-5SynthesisFullReportAPRILIND.pdf 